\title{
Preparation of a highly efficient Pt/USY catalyst for hydrogenation and selective ring-opening reaction of tetralin
}

\author{
Qi Wang ${ }^{1} \cdot$ Zhang-Gui Hou$^{2} \cdot$ Bo Zhang ${ }^{1} \cdot$ Jian Liu ${ }^{1} \cdot$ Wei-Yu Song ${ }^{1} \cdot$ De-Sheng Xue ${ }^{1} \cdot$ Li-Zhi Liu $^{2} \cdot$ \\ Dong Wang ${ }^{2} \cdot$ Xin-Guo Chen ${ }^{2}$
}

Received: 10 August 2017 / Published online: 26 March 2018

(C) The Author(s) 2018

\begin{abstract}
Ultrastable Y zeolite (USY)-supported Pt catalyst was prepared by gas-bubbling-assisted membrane reduction. The influence of reaction conditions and the metal and acid sites of catalysts on the catalytic performance of catalyst in hydrogenation and selective ring opening of tetralin, 1,2,3,4-tetrahydronaphthalene (THN), was studied. It was found that the optimal reaction conditions were at a temperature of $280{ }^{\circ} \mathrm{C}$, hydrogen pressure of $4 \mathrm{MPa}$, liquid hourly space velocity of $2 \mathrm{~h}^{-1}$ and $\mathrm{H}_{2} /$ THN ratio of 750. Under these optimal conditions, a high conversion of almost $100 \%$ was achieved on the 0.3Pt/USY catalyst. XRD patterns and TEM images revealed that Pt particles were highly dispersed on the USY, favorable to the hydrogenation reaction of tetralin. Ammonia temperature-programmed desorption and Py-IR results indicated that the introduction of Pt can reduce the acid sites of USY, particularly the strong acid sites of USY. Thus, the hydrocracking reaction can be suppressed.
\end{abstract}

Keywords Hydrogenation and selective ring opening $\cdot$ Reaction conditions $\cdot$ Supported Pt catalyst $\cdot$ Tetralin

\section{Introduction}

Diesel fuel is an important part of the worldwide energy mix. Nowadays, vast amounts of diesel fuel are produced from fluid catalytic cracking (FCC) technology (Wang et al. 2013a). However, FCC diesel exhibits low cetane number $(\mathrm{CN})$ and high aromatic content (Arribas and Martínez 2002). The unqualified diesel can cause incomplete combustion and the formation of undesirable emissions (Calemma et al. 2013). For the aim of environment protection, production of clean diesel fuel is needed. Hydrogenation and selective ring-opening (SRO) technology is a promising way to improve the $\mathrm{CN}$ of diesel fuel while minimizing the loss of diesel fraction (D'Ippolito

Edited by Xiu-Qin Zhu

Jian Liu

liujian@cup.edu.cn

1 State Key Laboratory of Heavy Oil Processing and Beijing Key Laboratory of Oil and Gas Pollution Control, China University of Petroleum, Beijing 102249, China

2 CNOOC Research Institute of Oil and Petrochemicals, Beijing 102249, China et al. 2017). Through the hydrogenation reaction, the aromatics are saturated. Then the rings of saturated aromatics are further selectively opened to form products with high $\mathrm{CN}$. Meanwhile, carbon losses are very little (McVicker et al. 2002). And the development of catalysts with high selectivity for ring opening has received increasing attention (Piccolo et al. 2012).

Ring opening of aromatics can be completed on either acid or noble metal catalysts, while a combination of the two functions is much more valid than just one (Rabl et al. 2011; Calemma et al. 2013). The existence of noble metals can increase the reactivity of aromatics hydrogenation. Hydrogenolysis of aromatics on metal catalysts is a favorable way for accomplishing SRO reaction (Benitez et al. 2017). Recent research proved that hydrogenation of aromatics should be accomplished ahead of ring opening (Do et al. 2006; Mouli et al. 2007; Ziaei-Azad and Sayari 2016). Pt catalysts have been widely studied in many reactions (Mouli et al. 2012; Wang et al. 2017a; Luo et al. 2017). The existence of $\mathrm{Pt}$ active sites can facilitate the adsorption of hydrogen and the efficient activation of hydrogenation reactions (Haas et al. 2012). Compared with other catalysts, zeolite-supported Pt catalysts have displayed higher activity for the hydrogenation reaction 
(Schmitz et al. 1996; Song et al. 2004). In addition, zeolitesupported Pt catalysts can promote the complete hydrogenation of naphthalene at low temperature (Song and Schmitz 1997).

The performance of a zeolite in SRO reaction is related to its acidic property (Alzaid and Smith 2013; Vicerich et al. 2015). USY (ultrastable Y molecular sieve) shows excellent catalytic performance in SRO reactions (Galadima and Muraza 2016) due to its appropriate acidic components (Corma et al. 2001; Ding et al. 2006; Wang et al. 2013b). USY possesses a high surface area, suitably acidic sites and unique pore structure. USY has received a great attention due to its special physicochemical properties (Park et al. 2011; Zhou et al. 2013). Here we report the synthesis of USY-supported Pt catalyst for the hydrogenation and SRO reaction of tetralin. The effect of reaction conditions, acidity and metal active sites of Pt/USY on the ring-opening reaction of THN was studied, and the synergy effect between hydrogenation active sites and acid sites in Pt/USY was investigated.

\section{Experimental}

\subsection{Catalyst preparation}

USY was synthesized by ammonium exchange from $\mathrm{NaY}$. Then, the sample was hydrothermally treated at $550{ }^{\circ} \mathrm{C}$ for $2 \mathrm{~h}$. USY-supported Pt catalysts were prepared by the gasbubbling-assisted membrane reduction method which was developed in our group (Wei et al. 2011). In a typical synthesis process, $2 \mathrm{~mL}$ poly-( $N$-vinyl-2-pyrrolidone) (PVP) solution (PVP-to-deionized water ratio: 1/10) as a stabilizer was added into $50 \mathrm{~mL} \quad \mathrm{H}_{2} \mathrm{PtCl}_{6}$ solution $(0.3 \mathrm{mmol} / \mathrm{L})$. Then $1 \mathrm{~g}$ of USY zeolite support was dissolved into the solution. The obtained solution was stored in a precursor tank and driven by a peristaltic pump to keep circulation flow. After that, $\mathrm{NaBH}_{4}$ was added into the mixed solution. Then the solid was separated by a centrifuge. At last, the obtained solid was washed with deionized water three times, dried at $80{ }^{\circ} \mathrm{C}$ for a night and calcined in air at $350{ }^{\circ} \mathrm{C}$ for $180 \mathrm{~min}$. The amount of $\mathrm{Pt}$ loading was $0.3 \mathrm{wt} \%$, so the final catalyst is denoted as $0.3 \mathrm{Pt} / \mathrm{USY}$.

\subsection{Catalyst characterization}

Powder X-ray diffraction (XRD) profiles were determined using a Bruker D8 Advance X-ray diffractometer with $\mathrm{Cu}$ $\mathrm{K} \alpha_{1}(\lambda=0.15406 \mathrm{~nm})$ radiation, in a $2 \theta$ range of $5^{\circ}-50^{\circ}$. $\mathrm{N}_{2}$ adsorption-desorption isotherms and pore size distribution of the catalysts were obtained using a Micromeritics TriStar II 3020 apparatus. The samples were pre-degassed at $300{ }^{\circ} \mathrm{C}$ for $5 \mathrm{~h}$ before $\mathrm{N}_{2}$ adsorption-desorption. Transmission electron microscopy (TEM) images were obtained with a JEOL JEM 2100 TEM. $\mathrm{NH}_{3}$-TPD signals were collected on a DAS-7000. Prior to each test, the samples of $0.1 \mathrm{~g}$ were pre-treated at $350{ }^{\circ} \mathrm{C}$ in a $\mathrm{NH}_{3}$ flow (35 $\mathrm{mL} / \mathrm{min}$ ) for $90 \mathrm{~min}$, and then the sample was cooled down to $100{ }^{\circ} \mathrm{C}$. Subsequently, ammonia was adsorbed at this temperature for $30 \mathrm{~min}$ to ensure the sufficient adsorption of $\mathrm{NH}_{3}$. Before desorption, the sample was purged by a flowing $\mathrm{N}_{2}$ stream at $100{ }^{\circ} \mathrm{C}$ for $1 \mathrm{~h}$ to remove excessive and physically adsorbed $\mathrm{NH}_{3}$. Finally, the catalysts were heated by a flow $(35 \mathrm{~mL} / \mathrm{min})$ of pure $\mathrm{N}_{2}$ from 100 to $650{ }^{\circ} \mathrm{C}$ at a heating rate of $10{ }^{\circ} \mathrm{C} / \mathrm{min}$. The infrared spectroscopy of chemisorbed pyridine experiments was conducted on a Bruker EQUINOX 55 Fourier transform infrared spectroscopy (Py-IR) spectrometer. A 20-mg sample was fixed in an infrared cell. The catalysts were pre-degassed at $400{ }^{\circ} \mathrm{C}$ for $5 \mathrm{~h}$ before the adsorption of pyridine. Py-IR spectra were recorded in the temperature range between 200 and $350{ }^{\circ} \mathrm{C}$.

\subsection{Catalytic activity test}

Hydrogenation and selective ring opening of tetralin were carried out in a fixed bed reactor (internal diameter $20 \mathrm{~mm}$; length $450 \mathrm{~mm})$. All the catalysts were sieved to 40-60 mesh. For hydrogenation and selective ring opening of tetralin reaction, $1 \mathrm{~g}$ catalyst was placed in the constant temperature zone of the reactor and hydrogen was led to the system at the rate of $15 \mathrm{~mL} / \mathrm{min}$. The catalyst was reduced with hydrogen $(15 \mathrm{~mL} / \mathrm{min})$ for $4 \mathrm{~h}$ at $300{ }^{\circ} \mathrm{C}$. And then the model feed of THN was introduced by a micro-pump. The reaction conditions of the hydrogenation reaction were as follows: the temperature range of 200-350 ${ }^{\circ} \mathrm{C}$, under $\mathrm{H}_{2}$ atmosphere (pressure range of 2-6 MPa), a LHSV range of $1-4 \mathrm{~h}^{-1}$ and a $\mathrm{H}_{2} / \mathrm{THN}$ volume ratio of $500-850$. The steady reaction state was maintained for $4 \mathrm{~h}$. Then, the products were collected and analyzed. Reaction products were detected on a gas chromatograph (GC) with FID detector and analyzed by gas chromatography-mass spectrometry (GC-MS). All the reaction products detected on the GC were grouped according to the number of carbon atoms of the products. The products were grouped as follows: (a) $\mathrm{C}_{10}-$ : molecules containing less than 10 carbons. (b) $\mathrm{C}_{10}$ fractions: selective ring-opening products (ROP) with 10 carbons, $\mathrm{C}_{10}$ compounds with one or two $\mathrm{C}_{5}$ rings, both isomers of decalin (decahydronaphthalene): trans-decalin (transDHN) and cis-decalin (cis-DHN), and naphthalene. (c) $\mathrm{C}_{10}+$ : molecules containing more than 10 carbons. 


\section{Results and discussion}

\subsection{Structural and textural analyses}

$\mathrm{N}_{2}$ adsorption-desorption isotherms and pore size distributions of USY and 0.3Pt/USY were obtained. The physical properties of all the samples are shown in Table 1. BET surface areas $\left(S_{\mathrm{BET}}\right)$ and pore volumes $\left(V_{\mathrm{p}}\right)$ of all the samples were determined according to BET and $\mathrm{BJH}$ methods, respectively. The pore diameters $\left(d_{\mathrm{BJH}}\right)$ were obtained by the BJH method. The pore size distribution was centered at $6.3 \mathrm{~nm}$ for USY and at $6.2 \mathrm{~nm}$ for $0.3 \mathrm{Pt} /$ USY, and this can be ascribed to the inter-granular porosity of the samples. The pore diameter, surface area and pore volume of $0.3 \mathrm{Pt} / \mathrm{USY}$ were not significantly reduced, indicating that most of Pt nanoparticles were dispersed on the USY.

The XRD patterns of USY and 0.3Pt/USY samples are exhibited in Fig. 1. The diffraction peaks of USY and $0.3 \mathrm{Pt} / \mathrm{USY}$ samples all showed the characteristics of USY zeolites (Wang et al. 2017b), indicating that the loading of Pt particles did not damage the initial framework of USY.

TEM examination showed the dispersion of Pt particles on the surface of USY. Figure 2 presents TEM images of 0.3Pt/USY samples. Pt particles can offer active sites for the hydrogenation reaction of THN. To obtain the particle size distribution of $\mathrm{Pt}$ particles of $0.3 \mathrm{Pt} / \mathrm{USY}$, a statistical analysis was performed to study the size distribution of 300 Pt particles on the surface of $0.3 \mathrm{Pt} / \mathrm{USY}$ sample, and the results are shown in Fig. 3. It is shown that the mean diameter of Pt particles was $3.9 \mathrm{~nm}$.

\section{2 $\mathrm{NH}_{3}$-TPD results}

To further study the effect of acidity on the catalytic hydrogenation of THN, $\mathrm{NH}_{3}$-TPD experiments were carried out. Figure 4 shows $\mathrm{NH}_{3}$-TPD patterns of USY and $0.3 \mathrm{Pt} / \mathrm{USY}$. It can be found that there existed three types of acid sites. The desorption peak centered at $100-250{ }^{\circ} \mathrm{C}$ corresponded to the weak acid sites of the samples. The desorption peak of the medium acid sites of the samples centered in the range between 250 and $350{ }^{\circ} \mathrm{C}$, and the desorption peak at $350-550{ }^{\circ} \mathrm{C}$ corresponded to the strong acid sites of the catalysts (Ma et al. 2007). It can be seen that the total acid content of $0.3 \mathrm{Pt} / \mathrm{USY}$ catalyst decreased

Table 1 Textural properties of the samples

\begin{tabular}{llll}
\hline Samples & $S_{\mathrm{BET}}, \mathrm{m}^{2} / \mathrm{g}$ & $d_{\mathrm{BJH}}, \mathrm{nm}$ & $V_{\mathrm{p}}, \mathrm{cm}^{3} / \mathrm{g}$ \\
\hline USY & 613 & 6.3 & 0.12 \\
$0.3 \mathrm{Pt} / \mathrm{USY}$ & 586 & 6.2 & 0.11 \\
\hline
\end{tabular}

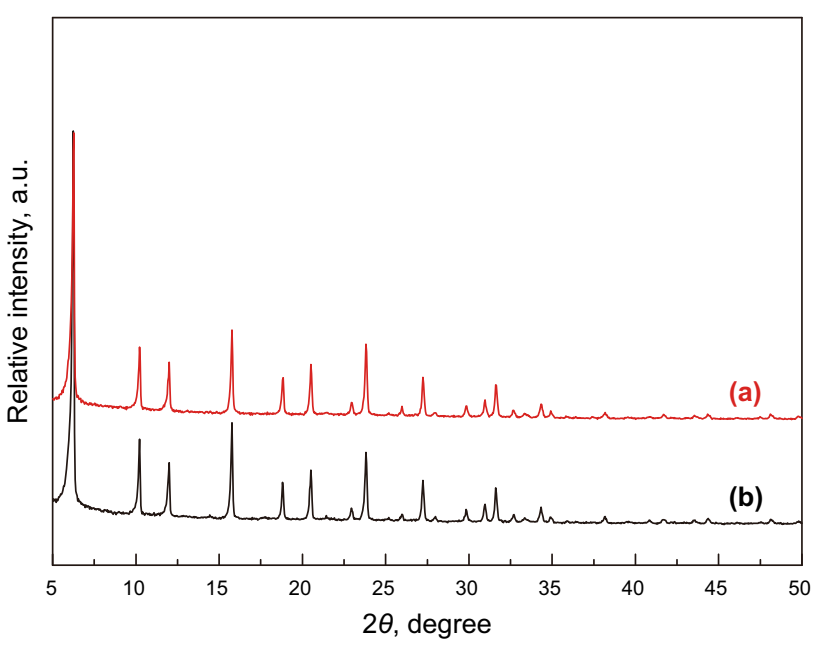

Fig. 1 Wide-angle XRD patterns of (a) USY and (b) $0.3 \mathrm{Pt} / \mathrm{USY}$

remarkably compared to that of USY. The peak intensities of the weak acid and medium acid sites of $0.3 \mathrm{Pt} / \mathrm{USY}$ slightly decreased, while the peak intensity of strong acid sites of $0.3 \mathrm{Pt} / \mathrm{USY}$ decreased greatly. It can be concluded that part of acid sites of USY was covered by the dispersed Pt particles.

\subsection{Py-IR results}

Acid type distribution of the catalysts is tested by Py-IR. The amounts of Brönsted (B) and Lewis (L) acid sites of samples are shown in Table 2. The results show that all the catalysts contain both B and L acid sites. It is generally believed that the desorption peak of pyridine at $200{ }^{\circ} \mathrm{C}$ is due to weak acid sites of samples. The desorption peak at $350{ }^{\circ} \mathrm{C}$ can be ascribed to strong acid sites (Wang et al. 2012). It can be seen that B and L acidity of $0.3 \mathrm{Pt} / \mathrm{USY}$ catalyst is significantly decreased. From the results of Table 2, the number of weak B and L acid sites of $0.3 \mathrm{Pt} /$ USY is slightly less than that of USY. Meanwhile, the strong $\mathrm{B}$ and $\mathrm{L}$ acid sites of $0.3 \mathrm{Pt} / \mathrm{USY}$ decrease remarkably from USY. It is in keeping with the results of $\mathrm{NH}_{3}$ TPD experiments.

\subsection{Catalytic performance}

\subsubsection{Influence of the space velocity}

The effect of LHSV on catalytic performance was studied at $T=260{ }^{\circ} \mathrm{C}, \mathrm{H}_{2} / \mathrm{THN}=500$ and hydrogen pressure of $4 \mathrm{MPa}$. Table 3 lists the hydrogenation and selective ringopening reaction results of THN at different LHSVs. $\mathrm{C}_{10}-$ and $\mathrm{C}_{10}+$ fraction yields were $6.7 \%$ and $12.0 \%$, respectively, when LHSV was $1 \mathrm{~h}^{-1}$. The ring-opening product content is the highest for selective ring-opening reactions 

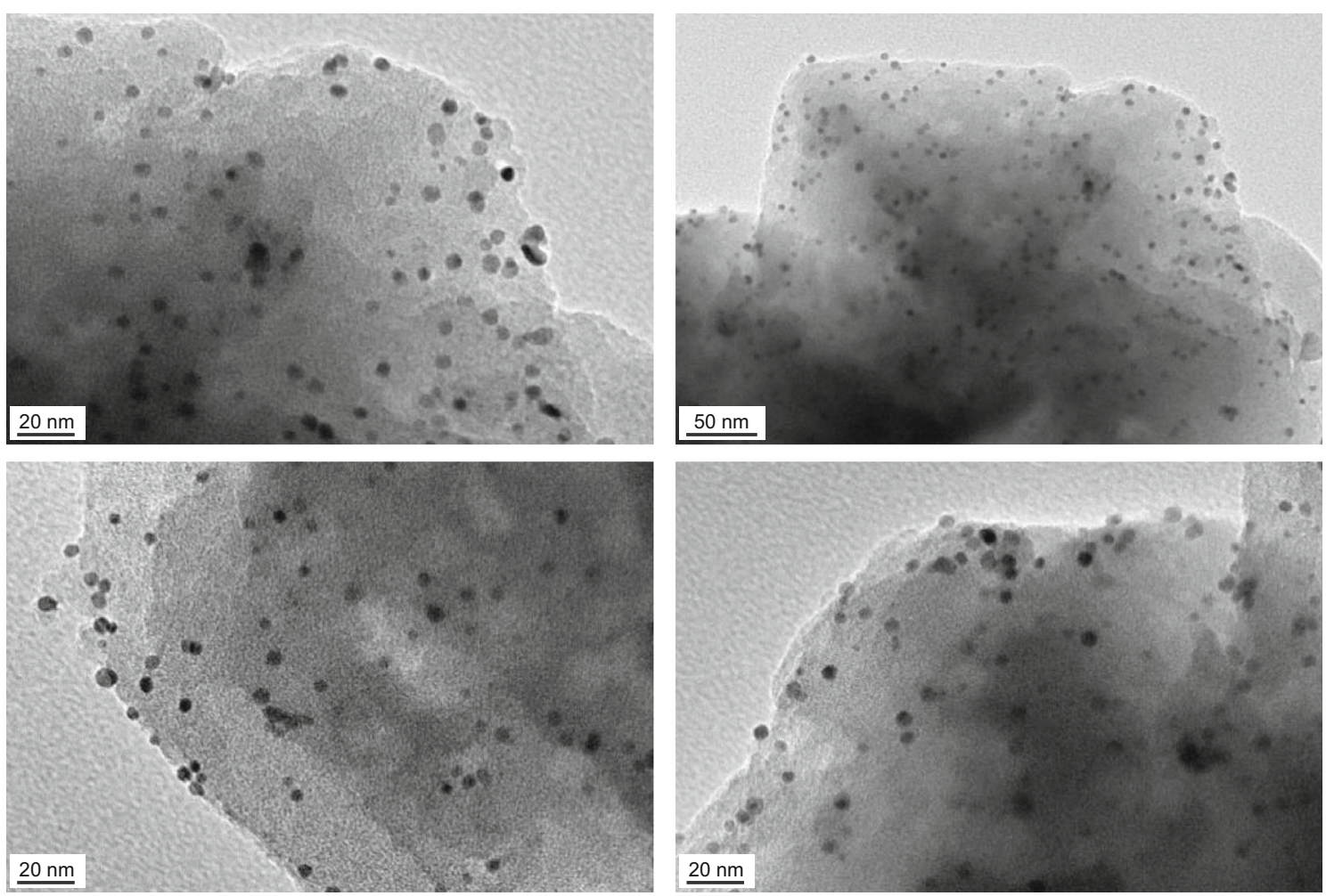

Fig. 2 TEM images of $0.3 \mathrm{Pt} / \mathrm{USY}$
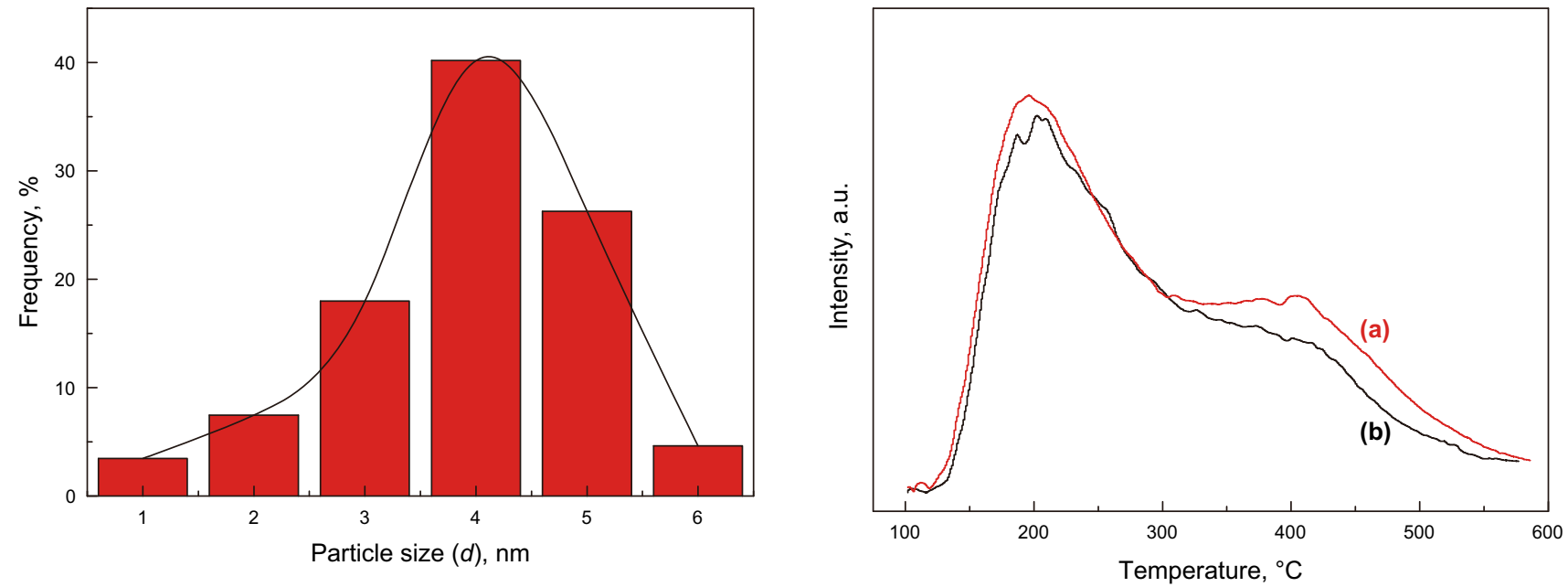

Fig. $3 \mathrm{Pt}$ particles size distribution of $0.3 \mathrm{Pt} / \mathrm{USY}$

of THN at different LHSVs (1, 2 and $\left.3 \mathrm{~h}^{-1}\right)$. It indicated that a low space velocity could facilitate the conversion of THN, while it promoted the cracking and condensation reactions. When LHSV increased from 1 to $2 \mathrm{~h}^{-1}$, the ROP (ring-opening products) yield significantly increased from $16.5 \%$ to $21.9 \%$, whereas the conversion of tetralin decreased from $91.6 \%$ to $89.7 \%$. When LHSV increased to $3 \mathrm{~h}^{-1}$, the conversion of tetralin was only $65.3 \%$. It is shown that the conversion of tetralin decreased with the increase in reaction space velocity. It was due to the short

Fig. $4 \mathrm{NH}_{3}$-TPD profiles of (a) USY and (b) $0.3 \mathrm{Pt} / \mathrm{USY}$ samples

contact time between tetralin and $0.3 \mathrm{Pt} / \mathrm{USY}$. A limited reaction of THN occurred. At LHSV $=2 \mathrm{~h}^{-1}$, the results of the conversion of THN and the selectivity of ROP were suited. Considering the obtained results, the optimal LHSV for hydrogenation and ring-opening reaction of tetralin is $2 \mathrm{~h}^{-1}$. 
Table 2 Amounts of Brönsted and Lewis acid sites of the catalysts determined by Py-IR

\begin{tabular}{|c|c|c|c|c|c|c|}
\hline \multirow[t]{2}{*}{ Samples } & \multicolumn{3}{|c|}{ Amount of acid sites at $200{ }^{\circ} \mathrm{C}, \mathrm{mmol} / \mathrm{g}$} & \multicolumn{3}{|c|}{ Amount of acid sites at $350{ }^{\circ} \mathrm{C}, \mathrm{mmol} / \mathrm{g}$} \\
\hline & $\mathrm{L}$ & B & $\mathrm{L}+\mathrm{B}$ & $\mathrm{L}$ & B & $\mathrm{L}+\mathrm{B}$ \\
\hline USY & 0.281 & 0.182 & 0.463 & 0.110 & 0.049 & 0.159 \\
\hline $0.3 \mathrm{Pt} / \mathrm{USY}$ & 0.219 & 0.127 & 0.346 & 0.054 & 0.028 & 0.082 \\
\hline
\end{tabular}

Table 3 Distribution of products at different liquid hourly space velocities

\begin{tabular}{lrrr}
\hline LHSV $^{-1} \mathrm{~h}^{-1}$ & \multicolumn{1}{c}{1} & \multicolumn{1}{c}{2} & \multicolumn{1}{c}{3} \\
\hline THN conversion, \% & 91.6 & 89.7 & 65.3 \\
C $_{10}-$ yield, \% & 6.7 & 1.8 & 1.7 \\
C $_{10}$ yield, \% & 71.6 & 79.6 & 56.6 \\
ROP yield, \% & 16.5 & 21.9 & 11.2 \\
$S_{\text {ROP }}$ & 18.0 & 24.4 & 17.2 \\
cis-decalin yield, \% & 5.9 & 6.7 & 6.9 \\
trans-decalin yield, \% & 45.0 & 49.9 & 28.5 \\
C $_{10}+$ yield, \% & 12.0 & 8.1 & 4.2 \\
\hline
\end{tabular}

$S_{\text {ROP }}$ denotes the selectivity of all the ring-opening products in the reaction

\subsubsection{Influence of $\mathrm{H}_{2} / \mathrm{THN}$ ratio}

The effect of $\mathrm{H}_{2} / \mathrm{THN}$ ratio was studied at $T=260{ }^{\circ} \mathrm{C}$, LHSV $=2 \mathrm{~h}^{-1}$ and hydrogen pressure of $4 \mathrm{MPa}$. As displayed in Fig. 5, the tetralin conversion and the yield of DHN increased remarkably with an increase in the $\mathrm{H}_{2} / \mathrm{THN}$ ratio from 500 to 750 . The reaction rate of THN cracking depended on the adsorption rate of the reactant molecules on the surface of the catalyst (Santikunaporn et al. 2004). The $\mathrm{H}_{2}$ /THN ratio is one of the important factors for the adsorption rate of THN on the surface of $0.3 \mathrm{Pt} / \mathrm{USY}$. The partial pressure of $\mathrm{H}_{2}$ increased regularly with the increase in the $\mathrm{H}_{2} / \mathrm{THN}$ ratio. It was beneficial to the adsorption and activation of $\mathrm{H}_{2}$ on the surface of $\mathrm{Pt} / \mathrm{USY}$, and the reaction rate of THN hydrogenation conversion was also elevated. When $\mathrm{H}_{2} / \mathrm{THN}$ ration was 500 , the yield of $\mathrm{C}_{10}+$ was $8.2 \%$. It was the highest $\mathrm{C}_{10}+$ content for the different $\mathrm{H}_{2} /$ THN ratios. The hydrogenation reaction is an exothermic reaction. When the $\mathrm{H}_{2} / \mathrm{THN}$ ratio is low, the different temperatures in the reactor will be very important. The higher temperature and a lower partial pressure of $\mathrm{H}_{2}$ can cause an increase in the dehydrogenation of THN. The higher $\mathrm{H}_{2}$ /THN ratio can prevent the formation of the coking precursor. However, the energy consumption of the device will increase with the increase in $\mathrm{H}_{2} / \mathrm{THN}$ ratio. Taking into account all the factors, the optimal $\mathrm{H}_{2} / \mathrm{THN}$ ratio was determined to be 750 .

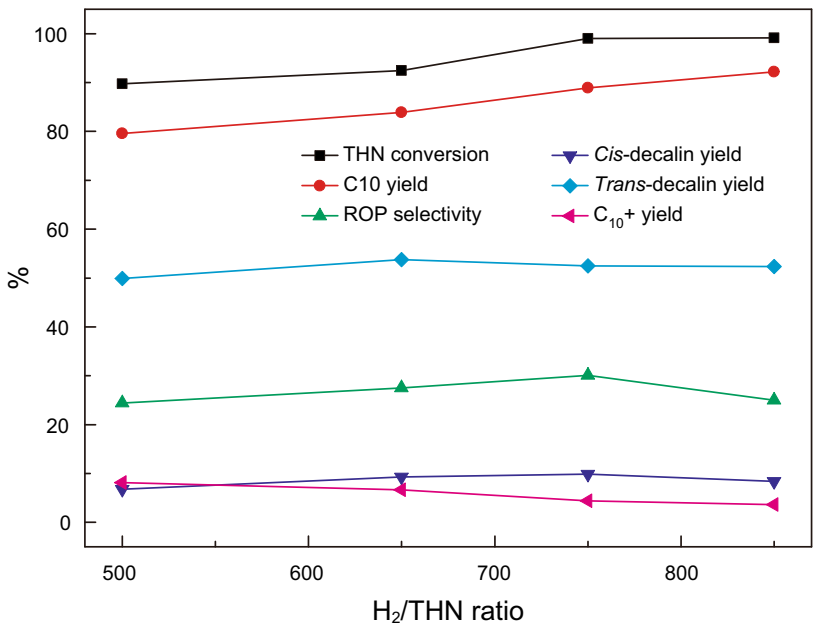

Fig. 5 Dependence of THN conversion on $\mathrm{H}_{2} / \mathrm{THN}$ ratio in the presence of $0.3 \mathrm{Pt} / \mathrm{USY}$ catalyst, and of ROP selectivity, yield of the main products on $\mathrm{H}_{2} / \mathrm{THN}$ ratio at $T=260{ }^{\circ} \mathrm{C}$, LHSV $=2 \mathrm{~h}^{-1}$ and hydrogen pressure of $4 \mathrm{MPa}$

\subsubsection{Influence of the hydrogen pressure}

The effect of the hydrogen pressure on tetralin conversion and yield of the main products was investigated at $T=260{ }^{\circ} \mathrm{C}, \mathrm{H}_{2} / \mathrm{THN}=750$ and $\mathrm{LHSV}=2 \mathrm{~h}^{-1}$. As shown in Fig. 6, the tetralin conversion, ROP selectivity and content of trans-DHN increased with an increase in the

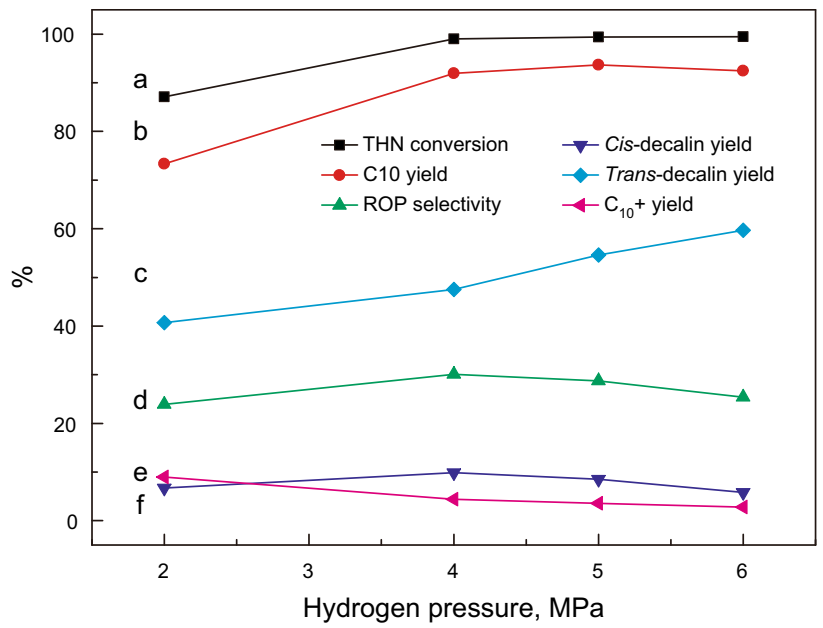

Fig. 6 Dependence of THN conversion on hydrogen pressure in the presence of the $0.3 \mathrm{Pt} / \mathrm{USY}$ catalyst, and of ROP selectivity and yield of main products on hydrogen pressure at $T=260{ }^{\circ} \mathrm{C}, \mathrm{H}_{2} / \mathrm{THN}=750$ and LHSV $=2 \mathrm{~h}^{-1}$ 
hydrogen pressure from 2 to $4 \mathrm{MPa}$. It is noted that the conversion of tetralin remained unchanged when the hydrogen pressure rose from 4 to $6 \mathrm{MPa}$, whereas the selectivity of ROP decreased from $30.1 \%$ to $25.4 \%$. It was indicated that the low hydrogen pressure was unfavorable to the hydrogenation of THN. When the hydrogen pressure was $2 \mathrm{MPa}$, the tetralin conversion was only $89 \%$. Meanwhile, an increase in $\mathrm{H}_{2}$ pressure would result in an increase in trans-DHN. When the hydrogen pressure was $4 \mathrm{MPa}$, ROP selectivity was $30.1 \%$. An increase in $\mathrm{H}_{2}$ pressure resulted in a decrease in the content of $\mathrm{C}_{10}+$. It indicated that the high $\mathrm{H}_{2}$ pressure was beneficial to suppressing the coking reaction. However, the high hydrogen pressure might lead to an increase in cost and safety risks. Taking into account the obtained results, the optimal hydrogen pressure for hydrogenation and selective ringopening reaction of THN was determined to be $4 \mathrm{MPa}$.

\subsubsection{Influence of the reaction temperature}

The effect of the reaction temperature is studied at LHSV $=2 \mathrm{~h}^{-1}, \mathrm{H}_{2} / \mathrm{THN}=750$ and hydrogen pressure of $4 \mathrm{MPa}$. The results are shown in Fig. 7. At the low temperature of $220{ }^{\circ} \mathrm{C}$, the conversion of THN was almost $100 \%$ and the selectivity of ring-opening product was only $8.95 \%$. It indicated that $0.3 \mathrm{Pt} / \mathrm{USY}$ possessed a high activity for the conversion of THN and an inferior selectivity of ROP at $220{ }^{\circ} \mathrm{C}$. With a temperature increase, the tetralin conversion could almost reach $100 \%$ in the range of $220-300{ }^{\circ} \mathrm{C}$. The selectivity to ROP regularly increased with increasing temperature. It was concluded that the high temperature could promote the THN ring-opening reaction. After the temperature rose from 280 to $300{ }^{\circ} \mathrm{C}$, the

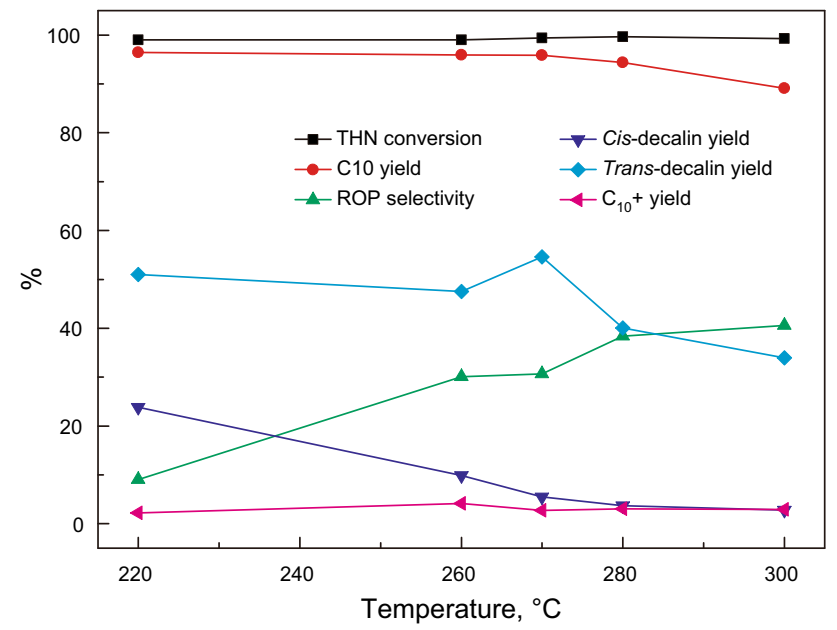

Fig. 7 Dependence of THN conversion on reaction temperature in the presence of $0.3 \mathrm{Pt} / \mathrm{USY}$ catalyst, and of ROP selectivity and yield of main products on temperature at $\mathrm{H}_{2} / \mathrm{THN}=750$, LHSV $=2 \mathrm{~h}^{-1}$ and hydrogen pressure of $4 \mathrm{MPa}$ conversion of THN was not significantly changed. Meanwhile, the content of $\mathrm{C}_{10}$ decreased from $94.4 \%$ to $89.1 \%$, which was due to the growth of the hydrocracking reaction of $\mathrm{C}_{10}$ and finally converting to $\mathrm{C}_{10}-$. These results indicated that the high temperature was useful for the hydrocracking reaction of $\mathrm{C}_{10}$. It was reported that the hydrocracking reaction was a sequential reaction of the ring opening (Ma et al. 2007). To obtain high yields of ROP and $\mathrm{C}_{10}$ fractions, the hydrocracking reaction should be avoided. Taking into account all the factors, the optimal temperature was determined to be $280{ }^{\circ} \mathrm{C}$.

\subsubsection{Role of the metal sites and acid sites}

The hydrogenation reactions of tetralin can take place on noble metal sites (Du et al. 2005). To determine the role of $\mathrm{Pt}$ in this reaction, the hydrogenation reactions of tetralin were tested over USY and 0.3Pt/USY at the optimum reaction conditions. The results of tetralin conversion, ROP selectivity and main products in the presence of USY and 0.3Pt/USY samples are listed in Table 4. For USY sample, the conversion of tetralin was only $29.4 \%$ and the yields of trans-DHN and cis-DHN were only $2.4 \%$ and $0.4 \%$. However, after the addition of Pt, the conversion of THN could reach to $99.6 \%$ and the yields of trans-DHN and cisDHN were enhanced to $40.1 \%$ and $3.7 \%$. It indicated that the hydrogenation of THN could take place on USY, but the rate was very low. However, the hydrogenation activity of USY was enhanced sharply with the incorporation of Pt. The low content of Pt and the dispersed Pt particles offer an abundance of the metallic centers for the hydrogenation reactions of THN. Based on the mechanism of bifunctional catalysis (Christoffel and Paál 1982), the acidic function acted as an important part in the SRO reaction. The acidic site is an important factor for the SRO reactions. 0.3Pt/ USY can give the appropriate acidic property. The weak acid sites can decrease the hydrocracking reactions. The strong acid sites of USY can lead to the hydrocracking of reactants. For the purpose of minimizing the loss of diesel

Table 4 Catalytic performances of USY and 0.3Pt/USY at the optimal reaction

\begin{tabular}{lrc}
\hline Samples & USY & $0.3 \mathrm{Pt} / \mathrm{USY}$ \\
\hline THN conversion, \% & 29.4 & 99.6 \\
$\mathrm{C}_{10}-$ yield, \% & 6.4 & 1.4 \\
$\mathrm{C}_{10}$ yield, \% & 12.8 & 94.4 \\
ROP yield, \% & 5.2 & 38.3 \\
$S_{\text {ROP }}$ & 17.7 & 38.5 \\
cis-decalin yield, \% & 0.4 & 3.7 \\
trans-decalin yield, \% & 2.4 & 40.1 \\
$\mathrm{C}_{10}+$ yield, \% & 3.5 & 3.0 \\
\hline
\end{tabular}


oil, the hydrocracking reactions should be avoided. From Table 4 , the yield of $\mathrm{C}_{10}-$ was $6.4 \%$ on USY. On $0.3 \mathrm{Pt} /$ USY, the introduction of $0.3 \% \mathrm{Pt}$ reduced the total number of the acid sites, especially the strong acid sites according to the results of $\mathrm{NH}_{3}$-TPD and Py-IR. The yield of the hydrocracking products reduced to $1.4 \%$ with the decrease in the acid sites.

\section{Conclusions}

In this work, $0.3 \mathrm{Pt} / \mathrm{USY}$ with low $\mathrm{Pt}$ content and highly dispersed Pt particles were prepared by the gas-bubblingassisted membrane reduction method. 0.3Pt/USY displayed excellent performance for the hydrogenation and selective ring opening of THN. The addition of Pt reduced the total number of the acid sites, especially the strong acid sites of USY. The optimal reaction conditions were a hydrogen pressure of $4 \mathrm{MPa}$, temperature of $280{ }^{\circ} \mathrm{C}$, LHSV of $2 \mathrm{~h}^{-1}$ and $\mathrm{H}_{2} / \mathrm{THN}$ ratio of 750 . The conversion of THN was almost $100 \%$, and the selectivity of ring-opening product was $38.5 \%$. The high conversion of THN and the good selectivity of ROP were due to sufficient metal sites and appropriate acid sites.

Acknowledgements The authors thank the National Natural Science Foundation of China (U1662103 and 21673290); the National HiTech Research and Development Program (863) of China (2015AA034603); and the China National Offshore Oil Corporation Fund (LHYJYKJSA20160002) for their funding.

Open Access This article is distributed under the terms of the Creative Commons Attribution 4.0 International License (http://creative commons.org/licenses/by/4.0/), which permits unrestricted use, distribution, and reproduction in any medium, provided you give appropriate credit to the original author(s) and the source, provide a link to the Creative Commons license, and indicate if changes were made.

\section{References}

Alzaid AH, Smith KJ. The kinetics of decalin ring opening over a Ir/ H-Beta catalyst. Appl Catal A. 2013;450:243-52. https://doi.org/ 10.1016/j.apcata.2012.10.010.

Arribas MA, Martínez A. The influence of zeolite acidity for the coupled hydrogenation and ring opening of 1-methylnaphthalene on Pt/USY catalysts. Appl Catal A. 2002;230(1):203-17. https:// doi.org/10.1016/S0926-860X(01)01015-8.

Benitez VM, de Lima SP, do Carmo Rangel M, et al. Influence of the metallic content on $\mathrm{Pt}-\mathrm{Ir} / \mathrm{Nb}_{2} \mathrm{O}_{5}$ catalysts for decalin selective ring opening. Catal Today. 2017;289:53-61. https://doi.org/10. 1016/j.cattod.2016.10.004.

Calemma V, Ferrari M, Rabl S, et al. Selective ring opening of naphthenes: from mechanistic studies with a model feed to the upgrading of a hydrotreated light cycle oil. Fuel. 2013;111:763-70. https://doi.org/10.1016/j.fuel.2013.04.055.

Christoffel EG, Paál Z. Activity and selectivity of bifunctional platinum catalysts in hydrocarbon reactions. $\mathrm{J}$ Catal.
1982;73(1):30-44.

https://doi.org/10.1016/00219517(82)90077-X.

Corma A, Martínez A, Martínez-Soria V. Catalytic performance of the new delaminated ITQ-2 zeolite for mild hydrocracking and aromatic hydrogenation processes. J Catal. 2001;200(2):259-69. https://doi.org/10.1006/jcat.2001.3219.

D'Ippolito SA, Ballarini AD, Pieck CL. Influence of support acidity and Ir content on the selective ring opening of decalin over Ir/ $\mathrm{SiO}_{2}-\mathrm{Al}_{2} \mathrm{O}_{3}$. Energy Fuels. 2017;31(5):5461-71. https://doi.org/ 10.1021/acs.energyfuels.7b00451.

Ding LH, Zheng Y, Zhang ZS, et al. Hydrotreating of light cycled oil using $\mathrm{WNi} / \mathrm{Al}_{2} \mathrm{O}_{3}$ catalysts containing zeolite beta and/or chemically treated zeolite Y. J Catal. 2006;241(2):435-45. https://doi.org/10.1016/j.jcat.2006.05.004.

Do PT, Alvarez WE, Resasco DE. Ring opening of 1,2- and 1,3dimethylcyclohexane on iridium catalysts. J Catal. 2006;238(2):477-88. https://doi.org/10.1016/j.jcat.2005.12.021.

Du HB, Fairbridge C, Yang H, et al. The chemistry of selective ringopening catalysts. Appl Catal A. 2005;294(1):1-21. https://doi. org/10.1016/j.apcata.2005.06.033.

Galadima A, Muraza O. Ring opening of hydrocarbons for diesel and aromatics production: design of heterogeneous catalytic systems. Fuel. 2016;181:618-29. https://doi.org/10.1016/j.fuel.2016.05.024.

Haas A, Rabl S, Ferrari M, et al. Ring opening of decalin via hydrogenolysis on Ir/- and Pt/silica catalysts. Appl Catal A. 2012;425:97-109. https://doi.org/10.1016/j.apcata.2012.03.010.

Luo $\mathrm{H}, \mathrm{Wu} \mathrm{XD}$, Weng D, et al. A novel insight into enhanced propane combustion performance on PtUSY catalyst. Rare Metals. 2017;36(1):1-9. https://doi.org/10.1007/s12598-016-0760-1.

Ma HJ, Yang XM, Wen GD, et al. Coupled hydrogenation and ring opening of tetralin on potassium modified Pt/USY catalysts. Catal Lett. 2007;116(3-4):149-54. https://doi.org/10.1007/ s10562-007-9103-z.

McVicker GB, Daage M, Touvelle MS, et al. Selective ring opening of naphthenic molecules. J Catal. 2002;210(1):137-48. https:// doi.org/10.1006/jcat.2002.3685.

Mouli KC, Sundaramurthy V, Dalai AK, et al. Selective ring opening of decalin with Pt-Ir on $\mathrm{Zr}$ modified MCM-41. Appl Catal A. 2007;321(1):17-26. https://doi.org/10.1016/j.apcata.2007.01. 031.

Mouli KC, Choudhary O, Soni K, et al. Improvement of cetane number of LGO by ring opening of naphthenes on Pt/Al-SBA-15 catalysts. Catal Today. 2012;198(1):69-76. https://doi.org/10. 1016/j.cattod.2012.01.027.

Park JI, Lee JK, Miyawaki J, et al. Hydro-conversion of 1-methyl naphthalene into (alkyl)benzenes over alumina-coated USY zeolite-supported NiMoS catalysts. Fuel. 2011;90(1):182-9. https://doi.org/10.1016/j.fuel.2010.09.002.

Piccolo L, Nassreddine S, Toussaint G, et al. Mechanism of tetralin ring opening and contraction over bifunctional $\mathrm{Ir} / \mathrm{SiO}_{2}-\mathrm{Al}_{2} \mathrm{O}_{3}$ catalysts. ChemSusChem. 2012;5(9):1717-23. https://doi.org/10. $1002 /$ cssc. 201200080 .

Rabl S, Santi D, Haas A, et al. Catalytic ring opening of decalin on Irand Pt-containing zeolite Y-influence of the nature of the chargecompensating alkali cations. Microporous Mesoporous Mater. 2011;146(1):190-200. https://doi.org/10.1016/j.micromeso. 2011.03.045.

Santikunaporn M, Herrera JE, Jongpatiwut S, et al. Ring opening of decalin and tetralin on $\mathrm{HY}$ and $\mathrm{Pt} / \mathrm{HY}$ zeolite catalysts. J Catal. 2004;228(1):100-13. https://doi.org/10.1016/j.jcat.2004.08.030.

Schmitz AD, Bowers G, Song CS. Shape-selective hydrogenation of naphthalene over zeolite-supported $\mathrm{Pt}$ and Pd catalysts. Catal Today. 1996;31(1-2):45-56. https://doi.org/10.1016/09205861(96)00033-8.

Song CS, Schmitz AD. Zeolite-supported Pd and Pt catalysts for lowtemperature hydrogenation of naphthalene in the absence and 
presence of benzothiophene. Energy Fuels. 1997;11(3):656-61. https://doi.org/10.1021/ef960179s.

Song YQ, Zhu XX, Xie SJ, et al. The effect of acidity on olefin aromatization over potassium modified ZSM-5 catalysts. Catal Lett. 2004;97(1):31-6. https://doi.org/10.1023/B:CATL. 0000034281.58853 .76$.

Vicerich MA, Benitez VM, Sánchez MA, et al. Influence of support material on the activity and selectivity of Pt-Ir catalysts for ring opening reactions. Catal Lett. 2015;145(3):910-8. https://doi. org/10.1007/s10562-014-1459-2.

Wang YD, Shen BJ, Hao K, et al. The combined modification of Ti and $\mathrm{P}$ to USY and its function in hydrogenation and ring opening reaction of tetralin. Catal Commun. 2012;25:59-63. https://doi. org/10.1016/j.catcom.2012.04.004.

Wang FJ, Zhang YY, Long XY, et al. Study on cetane number improvement of LCO by hydrotreating. Pet Process Petrochem. 2013a;44(10):27-31 (in Chinese).

Wang YD, Shen BJ, Wang L, et al. Effect of phosphorus modified USY on coupled hydrogenation and ring opening performance of $\mathrm{NiW} / \mathrm{USY}+\mathrm{Al}_{2} \mathrm{O}_{3}$ hydro-upgrading catalyst. Fuel Process Technol. 2013b;106:141-8. https://doi.org/10.1016/j.fuproc. 2012.07.014.
Wang Q, Liu J, Li YH, et al. Mesoporous $\mathrm{Co}_{3} \mathrm{O}_{4}$ supported $\mathrm{Pt}$ catalysts for low-temperature oxidation of acetylene. RSC Adv. 2017a;7(30):18592-600. https://doi.org/10.1039/C7RA02266B.

Wang YD, Zeng PH, Li H, et al. Influence of zirconium modified USY on coupled hydrogenation and ring opening of tetralin over $\mathrm{NiW} / \mathrm{USY}+\mathrm{Al}_{2} \mathrm{O}_{3}$. Catal Lett. 2017b;147(7):1704-13. https:// doi.org/10.1007/s10562-017-2075-8.

Wei YC, Liu J, Zhao Z, et al. Highly active catalysts of gold nanoparticles supported on three-dimensionally ordered macroporous $\mathrm{LaFeO}_{3}$ for soot oxidation. Angew Chem Int Ed. 2011;50(10):2326-9. https://doi.org/10.1002/anie.201006014.

Zhou LP, Shi MY, Cai QY, et al. Hydrolysis of hemicellulose catalyzed by hierarchical H-USY zeolites-the role of acidity and pore structure. Microporous Mesoporous Mater. 2013;169:54-9. https://doi.org/10.1016/j.micromeso.2012.10. 003.

Ziaei-Azad H, Sayari A. Bifunctional MCM-41 aluminosilicate supported Ir with adjusted metal and acid functionality for catalytic ring opening of 1, 2-dimethylcyclohexane. J Catal. 2016;344:729-40. https://doi.org/10.1016/j.jcat.2016.08.022. 